\title{
Role of trabectedin in the treatment of soft tissue sarcoma
}

REVIEW

This article was published in the following Dove Press journal:

OncoTargets and Therapy

5 May 2009

Number of times this article has been viewed

\author{
Alexandre Christinat \\ Serge Leyvraz \\ Centre Pluridisciplinaire d'Oncologie, \\ University Hospital, Lausanne, \\ Switzerland
}

\begin{abstract}
Interest in marine natural products has allowed the discovery of new drugs and trabectedin (ET-743, Yondelis), derived from the marine tunicate Ecteinascidia turbinata, was approved for clinical use in 2007. It binds to the DNA minor groove leading to interferences with the intracellular transcription pathways and DNA-repair proteins. In vitro antitumor activity was demonstrated against various cancer cell lines and soft tissue sarcoma cell lines. In phase I studies tumor responses were observed also in osteosarcomas and different soft tissue sarcoma subtypes. The most common toxicities were myelosuppression and transient elevation of liver function tests, which could be reduced by dexamethasone premedication. The efficacy of trabectedin was established in three phase II studies where it was administered at $1.5 \mathrm{mg} / \mathrm{m}^{2}$ as a $24 \mathrm{~h}$ intravenous infusion repeated every three weeks, in previously treated patients. The objective response rate was $3.7 \%-8.3 \%$ and the tumor control rate (which included complete response, partial response and stable disease) was obtained in half of patients for a median overall survival reaching 12 months. In nonpretreated patients the overall response rate was $17 \%$. Twenty-four percent of patients were without progression at six months. The median overall survival was almost 16 months with $72 \%$ surviving at one year. Predictive factors of response are being explored to identify patients who are most likely to respond to trabectedin. Combination with other agents are currently studied with promising results. In summary trabectedin is an active new chemotherapeutic agents that has demonstrated its role in the armamentarium of treatments for patients with sarcomas.
\end{abstract}

Keywords: soft tissue sarcoma, trabectedin, chemotherapy, DNA-minor groove binder

\section{Soft tissue sarcomas}

Soft-tissue sarcomas are a highly heterogeneous group of tumors with a low incidence. They account for $1 \%$ of all adult and $15 \%$ of pediatric malignancies. ${ }^{1,2}$ At least 50 different subtypes are distinguished, each with its specific biology and clinical outcome. The majority of these tumors are presumably derived from mesoderm and categorized by the normal tissue they resemble. As they are uncommon, however, they are subsumed under the collective term "soft-tissue sarcoma" and therapeutically approached in similar ways.

Despite adequate local treatment, up to one half of patients develop distant metastases. Most of these patients with advanced (ie, not resectable) or metastatic disease die from the disease after a median survival time from diagnosis ranging between eight to 12 months. ${ }^{3}$ The most common approach in all histological subtypes is to use doxorubicin and ifosfamide. ${ }^{4}$ Doxorubicin remains the reference in first line therapy with response rate of $20 \%-30 \%$ in large randomized trials. ${ }^{4-6}$ As a monotherapy,

submit your manuscript | www.dovepress.con 
ifosfamide yielded response rate similar to doxorubicin. ${ }^{5-8}$ It is widely used as second-line therapy after anthracycline failure with a response rate in the $10 \%-20 \%$ range. ${ }^{8,9}$

Combining these agents might be more effective but has not been shown to improve survival in a significant way compared to their use as single agents. ${ }^{6}$ Following suggestions that these agents may have a dose-response relationship, ${ }^{9-11}$ various phase-I and -II trials were performed in which they were administered at high doses, yielding response rates of $40 \%-66 \%{ }^{12-15,16}$ leading to median overall survival of up to 24 months in some studies. There are also suggestions that applying regimens with high response rates may render an initially inoperable tumor operable, thereby improving the outcome. ${ }^{17}$ But in two recent randomized trials, ${ }^{18-20}$ neither the response rate nor the overall survival could be improved by the intensification of chemotherapy, even if the progression-free survival was increased in one study. ${ }^{18}$

In recent years, progress has been made in understanding the clinical and biological complexity of sarcomas, ${ }^{21,22}$ such that oncologists have increasingly been able to define customized therapies. Paclitaxel has been found to be active mainly in patients with angiosarcomas. ${ }^{23}$ Docetaxel combined with gemcitabine has been shown to induce a 53\% response rate in leiomyosarcomas of gynecological origin. ${ }^{24}$ Topoisomerase inhibitors are active for rhabdomyosarcomas. ${ }^{25}$ And the identification of genetic abnormalities with the presence of fusion genes that are strongly associated with specific sarcoma subtypes has contributed towards understanding the biology of these tumors, and has facilitated their diagnosis. It has also opened new avenues for therapies targeted against the transcription pathways induced by these fusion proteins. ${ }^{26,27}$

In the past years, the interest in marine natural products has provided new possibilities of drug discovery. ${ }^{28}$ The first clinical agent derived from nucleosides obtained from marine sponge was cytosine arabinoside. Other marine compounds are in development such as aplidine obtained from the Mediterranean tunicate A. albicans or bryostatin from the bryozoan Bugula neritina. But trabectedin (ET-743, Ecteinascidin-743) is the first marine anticancer drug approved for clinical use in the European Union since 2007.

\section{Trabectedin}

Structure, mechanism of action, preclinical antitumor activity and phase I trials

Trabectedin (ET-743, Ecteinascidin, Yondelis) is a DNA-binding agent derived from the marine tunicate Ecteinascidia turbinata, now obtained by a semi-synthetic process starting with the antibiotic cynosafracin B. ${ }^{29,30}$ The molecule is comprised of three fused tetrahydroisoquinoline rings (Figure 1) of which two are covalently and reversibly bound to the DNA minor groove by a guanine specific alkylation at the N2 position. This induces a DNA bending towards the major groove. ${ }^{31,32}$ The third ring, being unbound, could interact with nuclear proteins. The transcriptional activation of inducible genes is inhibited, depending on the presence of the DNA repair systems, particularly the transcription coupled nucleotide excision repair system. ${ }^{33}$ The sensitivity to trabectedin is related to the presence of active repair mechanisms. ${ }^{34} \mathrm{~A}$ cell cycle arrest at $\mathrm{G} 2 / \mathrm{M}$ and apoptosis is induced through a $\mathrm{p} 53$-independent process. ${ }^{35}$

In vitro, trabectedin has a broad spectrum of activity in human primary tumor cells. ${ }^{36}$ The drug was very active against several different sarcoma cell lines ${ }^{37}$ and the results of activity in human tumor xenografts demonstrated activity in melanoma, non-small cell lung cancer and ovarian cancer. $^{38,39}$

\section{Pharmacokinetics and phase I studies}

After infusion, trabectedin is rapidly cleared from plasma, undergoing an extensive hepatic metabolism mainly through the cytochrome P450 3A4. ${ }^{40}$ Trabectedin has a high apparent volume of distribution and a half-life of approximately 90 hours. ${ }^{41}$ It is mainly excreted in the feces but less than $1 \%$ is excreted unchanged in the urine or feces. ${ }^{42}$

In phase I studies (Table 1), different schedules were investigated in patients with solid tumors. This schedules range from an intravenous infusion over 1, 3, 24, or 72 hours every three weeks to a weekly infusion for three out of a four-week cycle. ${ }^{43-47}$ The dose-limiting toxicities (DLT) were mainly hematological (neutropenia, thrombocytopenia) and fatigue. Grade 3-4 hepatic toxicities were also DLT in some but not all trials. ${ }^{45,46}$ DLT were transient and not cumulative. Nausea and vomiting were managed with 5HT3-antagonists. Fatigue or asthenia grade 3-4 was also frequently described ( $8 \%$ to $50 \%$ ). Tumors responses were observed in soft tissue sarcoma, osteosarcoma, melanoma, and breast cancer.

Two schedules were recommended for further phase II studies: $1.5 \mathrm{mg} / \mathrm{m}^{2}$ as a 24-hour continuous infusion given every three weeks and $0.58 \mathrm{mg} / \mathrm{m}^{2}$ as a three-hour infusion given weekly for three out of four weeks.

\section{Phase II studies of trabectedin in pretreated sarcomas}

The efficacy of trabectedin was studied in four phase-II studies in pretreated soft tissue sarcoma from US and 


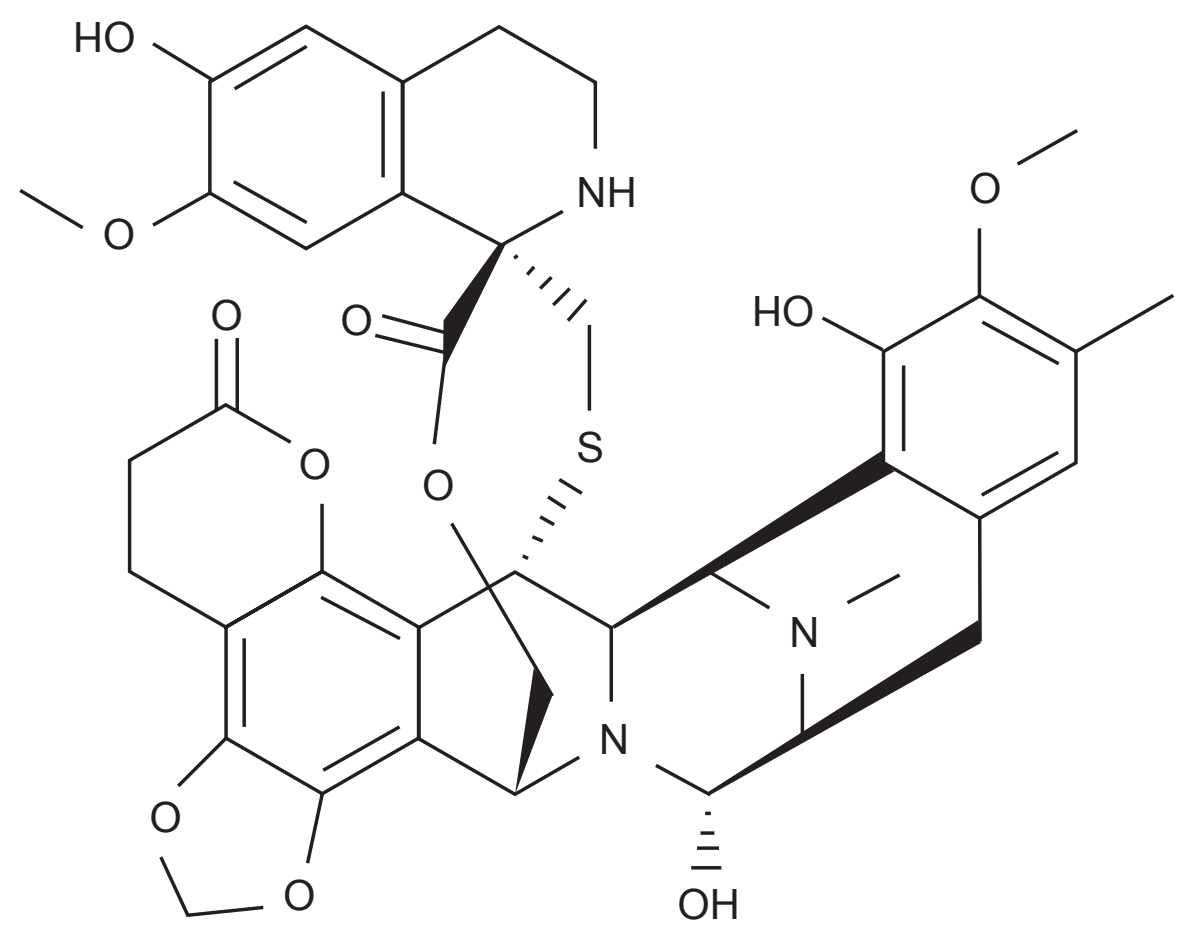

Figure I Structure of trabectedin.

Europe $^{48-50}$ of which one was a randomized phase II study comparing two different schedules ${ }^{51}$ (Table 2).

The first trial, published in 2004 by Yovine and colleagues, ${ }^{48}$ investigated trabectedin $1.5 \mathrm{mg} / \mathrm{m}^{2}$ administered as a 24-hour continuous infusion. Fifty-four patients were enrolled and analyzed in two predefined groups. The first group of 26 patients was pretreated with only one or two single agents or one combination regimen and the second group of 28 patients were heavily pretreated with at least three chemotherapeutic agents or two combinations. The predominant histology was leiomyosarcoma $(n=22$, of uterine origin $(n=8))$, and liposarcoma $(n=6)$. Two partial responses $(3.7 \%$ [95\% confidence interval (CI): $0.5 \%-12.8 \%]$ ) were reported and both had uterine leiomyosarcoma, four (7.4\%) patients had a minor response, and nine $(17 \%)$ patients had stable disease. Among the six responding patients, five received prior chemotherapy with ifosfamide and doxorubicin. The median progressionfree survival was 1.9 months after a median follow-up of 26 months. At three and six months, 38.8\% and 24.1\% of patients were progression-free, respectively. No difference was noted in progression-free survival between the two groups. But the less pre-treated patients had a longer median overall survival of 13.7 months versus 7.9 months. Overall, the median survival was 12.8 months with $30 \%$ of patients alive at two years.
Garcia-Carbonero and colleagues reported the results of the phase II study with trabectedin $1.5 \mathrm{mg} / \mathrm{m}^{2}$ administered as a 24-hour continuous infusion, conducted in 36 patients pretreated with up to two prior chemotherapy regimens. ${ }^{50}$ Some histological subtypes were excluded as gastrointestinal stromal tumors (GIST), mesothelioma, osteosarcoma, carcinosarcoma, Kaposi's sarcoma, or rhabdomyosarcoma. And the main histologies were leiomyosarcomas $(n=13)$, liposarcomas $(n=10)$, and synovial sarcomas $(n=6)$. One complete response (CR) was obtained in a patient with liposarcoma, and two partial responses (PR) in a patient with leiomyosarcoma and in a patient with liposarcoma, for an overall response rate of $8 \%$ (95\% CI: $2 \%-23 \%)$. Two other patients had a minor response. The median time to progression was 1.7 months and the median overall survival was 12.1 months with an overall survival rate at one year of $53.1 \%$.

The third study published by Le Cesne and colleagues ${ }^{49}$ was conducted in eight European centers by the European Organisation for Research and Treatment of Cancer (EORTC) and administered trabectedin at $1.5 \mathrm{mg} / \mathrm{m}^{2}$ as a 24-hour continuous infusion. One hundred and four patients were accrued with progressive soft tissue sarcomas excluding GIST. Most patients had leiomyosarcomas $(n=43)$, synovial sarcomas $(n=18)$, or liposarcomas $(n=10)$. There were eight partial responses (in leiomyosarcomas [ $n=5]$, synovial sarcoma $[n=1]$, liposarcoma $[n=1]$, and malignant fibrous 
Table I Dose-limiting toxicity (DLT) and maximum tolerated dose (MTD) in Phase I studies

\begin{tabular}{|c|c|c|c|c|c|}
\hline Reference & Schedule & $\mathbf{N}$ & MTD & DLT & $\begin{array}{l}\text { Recommended } \\
\text { dose for phase II }\end{array}$ \\
\hline Ryan $^{44}$ & $72 \mathrm{~h}$ infusion every 3 weeks & 21 & $1.2 \mathrm{mg} / \mathrm{m}^{2}$ & $\begin{array}{l}\text { Transamanitis, rhabdomyolysis, } \\
\text { neutropenia }\end{array}$ & $1.05 \mathrm{mg} / \mathrm{m}^{2}$ \\
\hline Taamma $^{45}$ & $24 \mathrm{~h}$ infusion every 3 weeks & 52 & $1.8 \mathrm{mg} / \mathrm{m}^{2}$ & Neutropenia, thrombocytopenia & $1.5 \mathrm{mg} / \mathrm{m}^{2}$ \\
\hline \multirow[t]{2}{*}{ Twelves ${ }^{46}$} & I h infusion every 3 weeks & 40 & $1.1 \mathrm{mg} / \mathrm{m}^{2}$ & Fatigue, neutropenia, thrombocytopenia & $\mathrm{I} \mathrm{mg} / \mathrm{m}^{2}$ \\
\hline & $3 \mathrm{~h}$ infusion every 3 weeks & 32 & $1.8 \mathrm{mg} / \mathrm{m}^{2}$ & $\begin{array}{l}\text { Fatigue, hyperbilirubinemia, } \\
\text { thrombocytopenia. }\end{array}$ & $1.65 \mathrm{mg} / \mathrm{m}^{2}$ \\
\hline Villalona-Calero ${ }^{47}$ & $\begin{array}{l}\text { Daily for five days every } \\
3 \text { weeks }\end{array}$ & 42 & $0.325 \mathrm{mg} / \mathrm{m}^{2} / \mathrm{d}$ & Neutropenia, thrombocytopenia & $0.325 \mathrm{mg} / \mathrm{m}^{2} / \mathrm{d}$ \\
\hline Farouzeh $^{43}$ & $\begin{array}{l}3 \mathrm{~h} \text { infusion weekly for three } \\
\text { weeks of a four week cycle }\end{array}$ & 31 & $0.65 \mathrm{mg} / \mathrm{m}^{2}$ & Neutropenia and hyperbilirubinemia & $0.58 \mathrm{mg} / \mathrm{m}^{2}$ \\
\hline
\end{tabular}

histiocytoma $[n=1])$ and forty-five $(40.5 \%)$ stable disease. Disease stabilization longer than six months was measured in $26 \%$ of patients. Of note the tumor control rate (defined as non progressing patients) reached $56 \%$ in leiomyosarcomas, $61 \%$ in synovial sarcomas, and $40 \%$ in liposarcomas. After a median estimated follow-up of 34 months, the median time to progression was 3.4 months. The progression-free rates at 3, 6, and 12 months were respectively 52\%, 29\%, and 17\%. GIST histology has been evaluated separately. Among 28 patients none responded and the best effect was disease stabilization in nine patients. The median time to progression was less than two months allowing to conclude that trabectedin was ineffective in GIST when given alone with this schedule. ${ }^{52}$

The results of these three phase $\mathrm{II}^{48-50}$ studies involving 183 patients were pooled and analyzed by Le Cesne. ${ }^{53}$
Leiomyosarcoma remained the main histological subtype representing $41 \%$ of patients followed by liposarcoma in $14 \%$ and synovial sarcoma in $11 \%$. Most patients $(95 \%)$ were pretreated with anthacyclines or ifosfamide and 113 patients were resistant to anthracyclines, 81 resistant to ifosfamide, and 63 to both agents. The overall response rate was $7.7 \%$. The clinical benefit, defined as the combination of the rate of objective response and of minor response and of stable disease, was $51.5 \%$. The median overall survival was 10.3 months with an overall survival rate at one year of $47.5 \%$ and a progression-free survival rate at six months of $19.8 \%$. The clinical benefit was similar in patients with bulky disease, with multiple pretreatments, with short previous progression-free survival or with early resistance to standard chemotherapy, suggesting the lack of cross resistance and a specific mechanism of action. ${ }^{54}$

Table 2 Efficacy and survival data of trabectedin in phase II trials

\begin{tabular}{|c|c|c|c|c|c|c|c|}
\hline Reference & Study type & $\mathbf{N}$ & $\begin{array}{l}\text { Subtype } \\
\text { of sarcoma }\end{array}$ & Overall response & Disease control & $\begin{array}{l}\text { Median TTP } \\
\text { (months) }\end{array}$ & $\begin{array}{l}\text { Median OS } \\
\text { (months) }\end{array}$ \\
\hline \multirow[t]{2}{*}{ Yovine $^{48}$} & \multirow[t]{2}{*}{ Phase II, second line } & 28 & LMS/Lipo & 2 & \multirow{2}{*}{$24 \%$ at six months } & \multirow{2}{*}{1.9} & \multirow{2}{*}{12.8} \\
\hline & & 22 & Other & $3.7 \%$ & & & \\
\hline \multirow[t]{2}{*}{ Garcia-Carbonero ${ }^{50}$} & \multirow[t]{2}{*}{ Phase II, second line } & 23 & LMS/Lipo & 3 & \multirow{2}{*}{ ND } & \multirow{2}{*}{1.7} & \multirow{2}{*}{12.1} \\
\hline & & 13 & Other & $8.3 \%$ & & & \\
\hline \multirow[t]{2}{*}{ Le Cesne ${ }^{49}$} & \multirow[t]{2}{*}{ Phase II, second line } & 53 & LMS/Lipo & 6 & \multirow{2}{*}{$53.6 \%$} & \multirow{2}{*}{3.5} & \multirow{2}{*}{9.3} \\
\hline & & 51 & Other & $8.1 \%$ & & & \\
\hline Pooled analysis Le & Phase II, second line & 183 & & $7.7 \%$ & $51.4 \%$ & ND & 10.3 \\
\hline Cesne AACR $2003^{53}$ & & & & & & & \\
\hline \multirow[t]{2}{*}{ Morgan ASCO $2007^{51}$} & \multirow[t]{2}{*}{ Phase II, second line } & 136 & 3-weekly & 5.6 & $38.9 \%$ & 3.7 & 13.8 \\
\hline & & 134 & weekly & 1.6 & $24.3 \%$ & 2.3 & 11.8 \\
\hline \multirow[t]{2}{*}{ Garcia-Carbonero ${ }^{61}$} & \multirow[t]{2}{*}{ Phase II, first line } & 24 & LMS/Lipo & 4 & \multirow{2}{*}{$20 \%$} & \multirow{2}{*}{1.6} & \multirow{2}{*}{15.8} \\
\hline & & 12 & Other & $17.1 \%$ & & & \\
\hline
\end{tabular}

Abbreviations: ND, no data; LMS, leiomyosarcoma; Lipo, liposarcoma; TTP, time to progression; OS, overall survival. 
A phase II randomized trial was conducted in patients with liposarcoma or leiomyosarcoma after failure of anthracyclines and ifosfamide..$^{51}$ Two hundred seventy patients received either trabectedin at $0.58 \mathrm{mg} / \mathrm{m}^{2}$ as a 3 h weekly infusion, three out of four weeks or at $1.5 \mathrm{mg} / \mathrm{m}^{2}$ as a $24 \mathrm{~h}$ continuous infusion every three weeks. A significantly longer time to progression was achieved for the three weekly regimen reaching 3.7 months and 2.3 months for the weekly regimen ( $p=0.0302$, hazard ratio [HR]: 0.734 ). The median overall survival was 13.8 months for the three weekly and 11.8 for the weekly regimen. The clinical benefit favored the three weekly regimen even if not statistically significant (58\% versus $44 \%$ ). Neutropenia grade 3-4 was described in $47 \%$ and $13 \%$ on the three weekly and the weekly arm, respectively, but it did not translate to a different rate of febrile neutropenia ( $0.8 \%$ ). Similarly grade $3-4$ transaminitis (ALAT) was more frequent in the three weekly arm (48\% versus $9 \%$ ), but without clinical consequences.

The results of the compassionate use programs in an unselected population, even though most of them included leiomyosarcomas or liposarcomas, were very similar in term of efficacy and toxicity. ${ }^{55-59}$ And in a historical comparison, progression-free survival of trabectedin was better than the other active chemotherapeutic agents. ${ }^{60}$

\section{First line trabectedin in sarcomas}

A phase II trial from Garcia-Carbonero and colleagues evaluated 36 patients with advanced or metastatic soft tissue sarcomas. ${ }^{61}$ The main histological subtypes were leiomyosarcomas $(n=15)$ and liposarcomas $(n=9)$. One complete response and five partial responses were observed for an overall response rate of $17.1 \%(95 \%$ CI: $6.6 \%-33.6 \%$ ). Responses occurred in three patients with liposarcoma, and one patient each with leiomyosarcoma, synovial sarcoma, and fibrosarcoma. One patient with a uterine leiomyosarcoma had a minor response. The median progression-free survival was 1.6 months and the progression-free rate at 6 months was $24.4 \%$. Median overall survival was 15.8 months and overall survival at one year was $72 \%$.

\section{Tolerability}

The toxicity profile encountered in the phase II trials was similar to the results observed in the phase I studies evaluating the 24-hour continuous infusion of trabectedin at the recommended dose. Myelosuppression and hepatic toxicity were the most frequently observed adverse events (Table 3). Despite neutropenia grade 3-4 in 33\%-61\% of patients, there was a low incidence of febrile neutropenia ( $6 \%-7 \%)$, quite different from other agents as doxorubicin (up to $19 \%)^{18,62}$ or ifosfamide regimens (up to $39 \%$ )., ${ }^{5,89}$ Thrombocytopenia and anemia grade $3-4$ was seen in $9 \%-22 \%$ of pretreated patients, but not in first line therapy.

Liver toxicity was frequent, but not cumulative and rapidly reversible. Transaminase elevation at more than five times the normal range was described in $20 \%$ to $57 \%$ of pretreated and $30 \%$ of the nonpretreated patients. This toxicity could be improved by dexamethasone premedication. In xenografts models, the hepatotoxicity induced by trabectedin was markedly reduced or avoided after administration of metabolism modulators such as dexamethasone or beta-naphtoflavone $24 \mathrm{~h}$ before trabectedin. ${ }^{63}$ The authors reported no difference in antitumor efficacy and hypothesized a decreased hepatic exposure to trabectedin, perhaps by regulation of hepatic metabolism. ${ }^{64}$ In the clinic dexamethasone premedication was retrospectively analyzed by Grosso and colleagues. ${ }^{55}$ Twenty-three patients treated with trabectedin 1.0 to $1.65 \mathrm{mg} / \mathrm{m}^{2}$ as a three-hour or 24 -hour continuous infusion every 21 days did not receive premedication whereas 31 patients received dexamethasone $4 \mathrm{mg}$ per os

Table 3 Incidence of grade 3/4 toxicities in phase II trials

\begin{tabular}{|c|c|c|c|c|c|c|c|c|}
\hline Reference & & $\mathbf{N}$ & Neutropenia & $\begin{array}{l}\text { Febrile } \\
\text { neutropenia }\end{array}$ & $\begin{array}{l}\text { Thrombocy- } \\
\text { topenia }\end{array}$ & Transaminitis & Nausea & $\begin{array}{l}\text { Asthenial } \\
\text { fatigue }\end{array}$ \\
\hline Yovine $^{48}$ & $\begin{array}{l}\text { Phase II, } \\
\text { second line }\end{array}$ & 54 & $33(61 \%)$ & $4(7 \%)$ & $10(19 \%)$ & $\begin{array}{l}26 \text { (48\%) ASAT } \\
3 \text { I (57 \%) ALAT }\end{array}$ & $4(7 \%)$ & $8(15 \%)$ \\
\hline Garcia-Carbonero ${ }^{50}$ & $\begin{array}{l}\text { Phase II, } \\
\text { second line }\end{array}$ & 36 & $12(34 \%)$ & $2(6 \%)$ & $6(17 \%)$ & $\begin{array}{l}9 \text { (26\%) ASAT } \\
7(20 \%) \text { ALAT }\end{array}$ & $2(6 \%)$ & 0 \\
\hline Le Cesne ${ }^{49}$ & $\begin{array}{l}\text { Phase II, } \\
\text { second line }\end{array}$ & 104 & $52(52.5 \%)$ & $9(9.1 \%)$ & 18 (I8.2\%) & $\begin{array}{l}35 \text { (35.3\%) ASAT } \\
44 \text { (44.5\%) ALAT }\end{array}$ & 7 (7.l\%) & 0 \\
\hline Garcia-Carbonero ${ }^{61}$ & $\begin{array}{l}\text { Phase II, } \\
\text { first line }\end{array}$ & 36 & $12(33 \%)$ & 0 & 0 & $\begin{array}{l}12(34 \%) \text { ASAT } \\
13(36 \%) \text { ALAT }\end{array}$ & $5(14 \%)$ & $4(11 \%)$ \\
\hline
\end{tabular}

Abbreviations: ALAT, alanine aminotransferase;ASAT, aspartate aminotransferase. 
bid 24 hours before therapy. The incidence of grade 3-4 transaminitis was reduced from $70 \%$ to $3 \%$ of patients by the dexamethasone premedication. The incidence of neutropenia and thrombocytopenia was also less important at 10\% and $0 \%$ instead of $39 \%$ and $35 \%$, respectively. The antitumor activity was similar between the two groups and comparable to the ones reported in other phase II trials. The overall response rate was $9 \%$ and the median progression-free survival was 2.6 months.

The analysis of four treatment-related deaths in the European phase II study ${ }^{49}$ revealed a statistical correlation between these severe toxicities and liver dysfunction. The influence of patient characteristics and pathophysiological variables was analyzed in 69 patients treated in phase II studies. ${ }^{65}$ The incidence of severe toxicity was significantly $(\mathrm{p}=0.02)$ greater for patients with any baseline liver function test exceeding the upper limit of the normal range. Thus the administration of the full dose of trabectedin at $1.5 \mathrm{mg} / \mathrm{m}^{2}$ requires normal alkaline phosphatase and transaminase levels, checked before each cycle, and the dose should be reduced to $1.2 \mathrm{mg} / \mathrm{m}^{2}$ in case of abnormal bilirubin level, and more than 2.5 increase of transaminase or alkalin phosphatase above the normal range.

Other frequent toxicities included nausea, vomiting and fatigue that could be grade 3-4 in up to $9 \%$ of patients. Elevation of creatine phosphokinase (CK) has been reported in $26 \%$ of patients and a few cases of severe and fatal rhabdomyolysis have been observed in the phase I-II studies. ${ }^{44,48,66}$ By an unknown mechanism, trabectedin induced necrosis of skeletal muscle resulting in subsequent release of intracellular contents leading to electrolyte imbalance, renal failure and death. Caution should be taken when used with other medications known to cause muscle injury as statins. $\mathrm{CK}$ is the most sensitive indicator of muscle injury and should be $\leq 2.5 \times$ upper limit of normal before each treatment and closely monitored during therapy.

\section{Perspective}

\section{Predictive factors of response}

The mechanism of action of trabectedin is not well understood, but it acts partially through interferences with the transcription pathways. ${ }^{67-69}$ The sensitivity of myxoid liposarcoma carrying a specific chromosomal translocation $\mathrm{t}(12 ; 16)(\mathrm{q} 13 ; \mathrm{p} 11)$ or $\mathrm{t}(12 ; 22)(\mathrm{q} 13 ; \mathrm{q} 12)$ that produce a DDIT3-FUS (DDIT3-EWSR1) fusion protein has been clinically recognized. ${ }^{62}$ Under treatment, the tissue density changes were consistent with a decrease in cellularity before tumor shrinkage, suggesting that it has modulated adipocyte differentiation. Recent in vivo data confirmed that trabectedin was able to induce a cascade of events leading to the activation of adipogenesis differentiation in cell lines presenting similar fusion genes. ${ }^{70}$ It opens interesting perspectives for the treatment of other translocation-related sarcomas and for the combination with other differentiating agents.

Trabectedin promotes DNA damage through its binding to $\mathrm{N} 2$ guanine in the minor groove causing a structural bending of DNA towards the major groove, and an unusual DNA helix distortion. This lesion is a substrate for the nucleotide excision repair (NER) pathway. In experimental models deficient cells in NER are insensitive to trabectedin. ${ }^{71}$ Thus the mRNA levels expression of ERCC1 (NER machinery), XPD (NER machinery), BRCA1 and BRCA2 were analyzed in 92 sarcoma patients by Schoeffski and colleagues. ${ }^{72}$ The six-month progressionfree survival and median overall survival were improved for patients with high expression levels of ERCC1 $(32 \%$ versus $15 \%$ and 12 months versus seven months, respectively). An increased six-month progression-free rate (33\% versus $11 \%$ ) and a longer median overall survival (15 versus five months) were significantly associated with low expression of BRCA1. No significant effect of XPD and BRCA2 was found on progression-free survival and overall survival. Some patients were highly sensitive to treatment when a high ERCC1 and a low BRCA1 expression were measured. They had a six-month progression-free survival of $50 \%$ and a median overall survival of 20.4 months. If the treatment of sarcomas by trabectedin should be based on a specific repair mechanism profile remains to be shown in a prospective study.

\section{Combinations}

Combination treatments with doxorubicin, ${ }^{73}$ irinotecan, ${ }^{74}$ and paclitaxe ${ }^{75}$ were evaluated in preclinical studies showing synergistic effects against sarcomas. Trabectedin was combined with doxorubicin, ${ }^{76,77}$ pegylated liposomal doxorubicin, ${ }^{77}$ paclitaxel, ${ }^{78}$ and capecitabine ${ }^{79}$ in phase I studies involving patients with solid tumors. The DLT were essentially myelosuppression and hepatotoxicity.

In sarcomas a phase I study combining doxorubicin and trabectedin reported that the maximum tolerated dose was $60 \mathrm{mg} / \mathrm{m}^{2}$ and $1.1 \mathrm{mg} / \mathrm{m}^{2}$ respectively. Preliminary pharmacokinetics of both agents were not significantly modified by the combination. Because of severe neutropenia at the first dose level, granulocyte colony-stimulating factor had to be added subsequently. The dose limiting toxicities were neutropenia and thrombopenia. Dose reduction was required 
in $51 \%$ of patients for trabectedin and $27 \%$ for doxorubicin. Among the 41 treated patients, five achieved a partial remission and 34 had a disease stabilization that lasted more than six months in 15 patients. $^{77}$

\section{Conclusion}

The marine-derived DNA-binding protein trabectedin induces DNA damage and transcriptional interference, which are dependent on the presence of DNA-repair systems. In phase I studies, the optimal dose and schedule of administration of trabectedin was $1.5 \mathrm{mg} / \mathrm{m}^{2}$ as a $24 \mathrm{~h}$ intravenous continuous infusion every three weeks. In pretreated patients, the three phase II studies involving 183 patients showed response rate up to $10 \%$ with disease control achieved in approximately $50 \%$ and a median overall survival of one year. Significant activity was also found in first line therapy with a response rate of $17 \%$ and $72 \%$ of patients surviving at one year. The treatment is generally well tolerated at the recommended dose. The most frequent severe toxicities were neutropenia, thrombocytopenia, and transient increase of hepatic tests. These adverse events were not cumulative and were rapidly reversible. Dexamethasone premedication reduced the hepatotoxicity and the myelosuppression. A better understanding of the mechanisms of action of trabectedin and its effect on transcription pathways make it a good candidate for combination with other chemotherapeutic agents or targeted therapy.

\section{Disclosure}

The authors report no conflicts of interest in this work.

\section{References}

1. Clark MA, Fisher C, Judson I, Thomas JM. Soft-tissue sarcomas in adults. N Engl J Med. 2005;353:701-711.

2. Casali PG, Jost L, Sleijfer S, Verweij J, Blay JY. Soft tissue sarcomas: ESMO clinical recommendations for diagnosis, treatment and follow-up. Ann Oncol. 2008;19(Suppl 2):ii89-ii93.

3. Adjuvant chemotherapy for localised resectable soft-tissue sarcoma of adults: meta-analysis of individual data. Sarcoma Meta-analysis Collaboration. Lancet. 1997;350:1647-1654.

4. Edmonson JH, Ryan LM, Blum RH, et al. Randomized comparison of doxorubicin alone versus ifosfamide plus doxorubicin or mitomycin, doxorubicin, and cisplatin against advanced soft tissue sarcomas. J Clin Oncol. 1993;11:1269-1275.

5. Lorigan P, Verweij J, Papai Z, et al. Phase III trial of two investigational schedules of ifosfamide compared with standard-dose doxorubicin in advanced or metastatic soft tissue sarcoma: a European Organisation for Research and Treatment of Cancer Soft Tissue and Bone Sarcoma Group Study. J Clin Oncol. 2007;25:3144-3150.

6. Santoro A, Tursz T, Mouridsen H, et al. Doxorubicin versus CYVADIC versus doxorubicin plus ifosfamide in first-line treatment of advanced soft tissue sarcomas: a randomized study of the European Organization for Research and Treatment of Cancer Soft Tissue and Bone Sarcoma Group. J Clin Oncol. 1995;13:1537-1545.
7. Serrone L, Zeuli M, Papaldo P, Nardoni C, Pacetti U, Cognetti F Ifosfamide and epirubicin combination in untreated sarcomas: two treatment schedules. Onkologie. 2001;24:465-468.

8. Nielsen OS, Judson I, van Hoesel Q, et al. Effect of high-dose ifosfamide in advanced soft tissue sarcomas. A multicentre phase II study of the EORTC Soft Tissue and Bone Sarcoma Group. Eur J Cancer. 2000;36:61-67.

9. Le Cesne A, Antoine E, Spielmann M, et al. High-dose ifosfamide: circumvention of resistance to standard-dose ifosfamide in advanced soft tissue sarcomas. J Clin Oncol. 1995;13:1600-1608.

10. Cerny T, Leyvraz S, von Briel T, et al. Saturable metabolism of continuous high-dose ifosfamide with mesna and GM-CSF: a pharmacokinetic study in advanced sarcoma patients. Swiss Group for Clinical Cancer Research (SAKK). Ann Oncol. 1999;10:1087-1094.

11. O’Bryan RM, Luce JK, Talley RW, Gottlieb JA, Baker LH, Bonadonna G. Phase II evaluation of adriamycin in human neoplasia. Cancer. 1973;32:1-8.

12. Frustaci S, Buonadonna A, Galligioni E, et al. Increasing 4'-epidoxorubicin and fixed ifosfamide doses plus granulocyte-macrophage colony-stimulating factor in advanced soft tissue sarcomas: a pilot study. J Clin Oncol. 1997; 15:1418-1426.

13. Maurel J, Fra J, Lopez-Pousa A, et al. Sequential dose-dense doxorubicin and ifosfamide for advanced soft tissue sarcomas: a Phase II trial by the Spanish Group for Research on Sarcomas (GEIS). Cancer. 2004;100:1498-1506.

14. Patel SR, Vadhan-Raj S, Burgess MA, et al. Results of two consecutive trials of dose-intensive chemotherapy with doxorubicin and ifosfamide in patients with sarcomas. Am J Clin Oncol. 1998;21:317-321.

15. Reichardt P, Tilgner J, Hohenberger P, Dorken B. Dose-intensive chemotherapy with ifosfamide, epirubicin, and filgrastim for adult patients with metastatic or locally advanced soft tissue sarcoma: a phase II study. J Clin Oncol. 1998;16:1438-1443.

16. Leyvraz $\mathrm{S}, \mathrm{Z}$ weifel $\mathrm{M}$, Jundt $\mathrm{G}$, et al. Long-term results of a multicenter SAKK trial on high-dose ifosfamide and doxorubicin in advanced or metastatic gynecologic sarcomas. Ann Oncol. 2006;17:646-651.

17. Judson I. Systemic therapy of soft tissue sarcoma: an improvement in outcome. Ann Oncol. 2004;15(Suppl 4):iv193-iv196.

18. Le Cesne A, Judson I, Crowther D, et al. Randomized phase III study comparing conventional-dose doxorubicin plus ifosfamide versus high-dose doxorubicin plus ifosfamide plus recombinant human granulocyte-macrophage colony-stimulating factor in advanced soft tissue sarcomas: A trial of the European Organization for Research and Treatment of Cancer/Soft Tissue and Bone Sarcoma Group. J Clin Oncol. 2000;18:2676-2684.

19. Verma S, Younus J, Stys-Norman D, Haynes AE, Blackstein M. Dose-intensive chemotherapy with growth factor or autologous bone marrow/stem cell transplant support in first-line treatment of advanced or metastatic adult soft tissue sarcoma: a systematic review. Cancer. 2008;112:1197-1205.

20. Fayette J, Penel N, Chevreau C, et al. Phase III trial of standard versus dose-intensified doxorubicin, ifosfamide and dacarbazine (MAID) in the first-line treatment of metastatic and locally advanced soft tissue sarcoma. Invest New Drugs. 2009. Jan 16. [Epub ahead of print].

21. Dirix LY, Van Oosterom AT. Soft tissue sarcoma in adults. Curr Opin Oncol. 1999;11:285-295.

22. Fayette J, Blay JY. Genetic predictors for drug resistance in soft tissue sarcoma: a review of publications in 2004. Curr Opin Oncol. 2005; 17:370-375.

23. Fata F, O'Reilly E, Ilson D, et al. Paclitaxel in the treatment of patients with angiosarcoma of the scalp or face. Cancer. 1999;86:2034-2037.

24. Hensley ML, Maki R, Venkatraman E, et al. Gemcitabine and docetaxel in patients with unresectable leiomyosarcoma: results of a phase II trial. J Clin Oncol. 2002;20:2824-2831.

25. Cosetti M, Wexler LH, Calleja E, et al. Irinotecan for pediatric solid tumors: the Memorial Sloan-Kettering experience. J Pediatr Hematol Oncol. 2002;24:101-105. 
26. Riggi N, Cironi L, Suva ML, Stamenkovic I. Sarcomas: genetics, signalling, and cellular origins. Part 1: The fellowship of TET. J Pathol. 2007;213:4-20.

27. Suva ML, Cironi L, Riggi N, Stamenkovic I. Sarcomas: genetics, signalling, and cellular origins. Part 2: TET-independent fusion proteins and receptor tyrosine kinase mutations. J Pathol. 2007;213:117-130.

28. Molinski TF, Dalisay DS, Lievens SL, Saludes JP. Drug development from marine natural products. Nat Rev Drug Discov. 2009;8:69-85.

29. Martinez EJ, Corey EJ. A new, more efficient, and effective process for the synthesis of a key pentacyclic intermediate for production of ecteinascidin and phthalascidin antitumor agents. Org Lett. 2000;2: 993-996.

30. Cuevas C, Perez M, Martin MJ, et al. Synthesis of ecteinascidin ET-743 and phthalascidin Pt-650 from cyanosafracin B. Org Lett. 2000;2:2545-2548.

31. Erba E, Bergamaschi D, Bassano L, et al. Ecteinascidin-743 (ET-743), a natural marine compound, with a unique mechanism of action. Eur J Cancer. 2001;37:97-105.

32. Zewail-Foote M, Hurley LH. Ecteinascidin 743: a minor groove alkylator that bends DNA toward the major groove. J Med Chem. 1999;42:2493-2497.

33. Takebayashi Y, Pourquier P, Zimonjic DB, et al. Antiproliferative activity of ecteinascidin 743 is dependent upon transcription-coupled nucleotide-excision repair. Nat Med. 2001;7:961-966.

34. Soares DG, Escargueil AE, Poindessous V, et al. Replication and homologous recombination repair regulate DNA double-strand break formation by the antitumor alkylator ecteinascidin 743. Proc Natl Acad Sci U S A. 2007;104:13062-13067.

35. Gajate C, An F, Mollinedo F. Differential cytostatic and apoptotic effects of ecteinascidin-743 in cancer cells. Transcription-dependent cell cycle arrest and transcription-independent JNK and mitochondrial mediated apoptosis. J Biol Chem. 2002;277:41580-41589.

36. Izbicka $\mathrm{E}$, Lawrence $\mathrm{R}$, Raymond $\mathrm{E}$, et al. In vitro antitumor activity of the novel marine agent, ecteinascidin-743 (ET-743, NSC-648766) against human tumors explanted from patients. Ann Oncol. 1998;9: 981-987.

37. Li WW, Takahashi N, Jhanwar S, et al. Sensitivity of soft tissue sarcoma cell lines to chemotherapeutic agents: identification of ecteinascidin-743 as a potent cytotoxic agent. Clin Cancer Res. 2001;7:2908-11.

38. Valoti G, Nicoletti MI, Pellegrino A, et al. Ecteinascidin-743, a new marine natural product with potent antitumor activity on human ovarian carcinoma xenografts. Clin Cancer Res. 1998;4:1977-1983.

39. Hendriks HR, Fiebig HH, Giavazzi R, Langdon SP, Jimeno JM, Faircloth GT. High antitumour activity of ET743 against human tumour xenografts from melanoma, non-small-cell lung and ovarian cancer. Ann Oncol. 1999;10:1233-1240.

40. Brandon EF, Meijerman I, Klijn JS, et al. In vitro cytotoxicity of ET-743 (Trabectedin, Yondelis), a marine anti-cancer drug, in the Hep G2 cell line: influence of cytochrome P450 and phase II inhibition, and cytochrome P450 induction. Anticancer Drugs. 2005;16:935-943.

41. van Kesteren C, Cvitkovic E, Taamma A, et al. Pharmacokinetics and pharmacodynamics of the novel marine-derived anticancer agent ecteinascidin 743 in a phase I dose-finding study. Clin Cancer Res. 2000;6:4725-4732.

42. Beumer JH, Rademaker-Lakhai JM, Rosing H, Lopez-Lazaro L, Beijnen JH, Schellens JH. Trabectedin (Yondelis, formerly ET-743), a mass balance study in patients with advanced cancer. Invest New Drugs. 2005;23:429-436.

43. Forouzeh B, Hidalgo M, Denis L, et al. Phase I and pharmacokinetic study of the marinederived DNA minor groove binder ET-743 on a weekly $\times 3$ every-4-week schedule in patients with advanced solid malignancies. Proc Am Soc Clin Oncol. 2001;20: Abstract \# 373.

44. Ryan DP, Supko JG, Eder JP, et al. Phase I and pharmacokinetic study of ecteinascidin 743 administered as a 72-hour continuous intravenous infusion in patients with solid malignancies. Clin Cancer Res. 2001;7:231-242.
45. Taamma A, Misset JL, Riofrio M, et al. Phase I and pharmacokinetic study of ecteinascidin-743, a new marine compound, administered as a 24-hour continuous infusion in patients with solid tumors. J Clin Oncol. 2001;19:1256-1265.

46. Twelves C, Hoekman K, Bowman A, et al. Phase I and pharmacokinetic study of Yondelis (Ecteinascidin-743; ET-743) administered as an infusion over $1 \mathrm{~h}$ or $3 \mathrm{~h}$ every 21 days in patients with solid tumours. Eur J Cancer. 2003;39:1842-1851.

47. Villalona-Calero MA, Eckhardt SG, Weiss G, et al. A phase I and pharmacokinetic study of ecteinascidin-743 on a daily $\times 5$ schedule in patients with solid malignancies. Clin Cancer Res. 2002;8:75-85.

48. Yovine A, Riofrio M, Blay JY, et al. Phase II study of ecteinascidin-743 in advanced pretreated soft tissue sarcoma patients. J Clin Oncol. 2004;22:890-899.

49. Le Cesne A, Blay JY, Judson I, et al. Phase II study of ET-743 in advanced soft tissue sarcomas: a European Organisation for the Research and Treatment of Cancer (EORTC) soft tissue and bone sarcoma group trial. J Clin Oncol. 2005;23:576-84.

50. Garcia-Carbonero R, Supko JG, Manola J, et al. Phase II and pharmacokinetic study of ecteinascidin 743 in patients with progressive sarcomas of soft tissues refractory to chemotherapy. J Clin Oncol. 2004;22:1480-1490.

51. Morgan JA, Le Cesne A, Chawla S, et al; Yondelis Sarcoma Study Group. Randomized phase II study of trabectedin in patients with liposarcoma and leiomyosarcoma (L-sarcomas) after failure of prior anthracylines (A) and ifosfamide (I). J Clin Oncol. 2007;25(June 20 Supplement):18S, ASCO Annual Meeting Proceedings Part I Vol 25, No 18S (June 20 Supplement), 10060.

52. Blay JY, Le Cesne A, Verweij J, et al. A phase II study of ET-743/ trabectedin ('Yondelis') for patients with advanced gastrointestinal stromal tumours. Eur J Cancer. 2004;40:1327-1331.

53. Le Cesne A, Misset JL, Demetri G, et al. Consistent evidence of activity of ecteinascidin (ET-743) in pretreated, advanced soft tissue sarcoma (ASTS): results from a pooled analysis of three pivotal phase II clinical trials (p2ct) and safety profile of a $24 \mathrm{~h}$ infusion schedule. European Journal of Cancer. 2001;37:S34-S.

54. D'Incalci M, Jimeno J. Preclinical and clinical results with the natural marine product ET-743. Expert Opin Investig Drugs. 2003;12:1843-1853.

55. Grosso F, Dileo P, Sanfilippo R, et al. Steroid premedication markedly reduces liver and bone marrow toxicity of trabectedin in advanced sarcoma. Eur J Cancer. 2006;42:1484-90.

56. Huygh G, Clement PM, Dumez H, et al. Ecteinascidin-743: evidence ofactivity in advanced, pretreated soft tissue and bone sarcoma patients. Sarcoma. 2006;56282.

57. Grosso. Trabectedin in Soft Tissue Sarcomas (STS) carrying a chromosomal translocation: an exploratory analysis. Seattle, WA: 13th CTOS meeting, Nov 1-3, 2007. Abstract \# 9002007.

58. Dileo M. Final results of a phase II trial of 3-hr infusion trabectedin in patients with recurrent sarcomas. Istanbul, Turkey: 31st ESMO Congress Sept 29 - Oct 3, 2006. Abstract \# 524P 2006

59. Mohan V. Updated results of Phase II study of trabectedin (ET-743) in pretreated patients with advanced/ metastatic soft tissue sarcoma from a single institute. Chicago, IL: ASCO American Society of Clinical Oncology, 44th Annual Meeting, May 30 - Jun 3, 2008. Abstract \# 215062008 .

60. Van Glabbeke M, Verweij J, Judson I, Nielsen OS. Progression-free rate as the principal end-point for phase II trials in soft-tissue sarcomas. Eur J Cancer. 2002;38:543-549.

61. Garcia-Carbonero R, Supko JG, Maki RG, et al. Ecteinascidin-743 (ET-743) for chemotherapy-naive patients with advanced soft tissue sarcomas: multicenter phase II and pharmacokinetic study. J Clin Oncol. 2005;23:5484-5492.

62. Grosso F, Jones RL, Demetri GD, et al. Efficacy of trabectedin (ecteinascidin-743) in advanced pretreated myxoid liposarcomas: a retrospective study. Lancet Oncol. 2007;8:595-602.

63. Donald S, Verschoyle RD, Greaves P, et al. Complete protection by high-dose dexamethasone against the hepatotoxicity of the novelantitumor drug yondelis (ET-743) in the rat. Cancer Res. 2003;63:5902-5908. 
64. Donald S, Verschoyle RD, Greaves P, Orr S, Jimeno J, Gescher AJ Comparison of four modulators of drug metabolism as protectants against the hepatotoxicity of the novel antitumor drug yondelis (ET-743) in the female rat and in hepatocytes in vitro. Cancer Chemother Pharmacol. 2004;53:305-312.

65. Puchalski TA, Ryan DP, Garcia-Carbonero R, et al. Pharmacokinetics of ecteinascidin 743 administered as a 24-h continuous intravenous infusion to adult patients with soft tissue sarcomas: associations with clinical characteristics, pathophysiological variables and toxicity. Cancer Chemother Pharmacol. 2002;50:309-319.

66. Skorupa A, Beldner M, Kraft A, Montero AJ. Fatal rhabdomyolysis as a complication of ET-743 (Yondelis) chemotherapy for sarcoma. Cancer Biol Ther. 2007;6(7):1015-1017.

67. Friedman D, Hu Z, Kolb EA, Gorfajn B, Scotto KW. Ecteinascidin-743 inhibits activated but not constitutive transcription. Cancer Res. 2002;62:3377-3381.

68. Jin S, Gorfajn B, Faircloth G, Scotto KW. Ecteinascidin-743, a transcription-targeted chemotherapeutic that inhibits MDR1 activation. Proc Natl Acad Sci U S A. 2000;97:6775-6779.

69. Minuzzo M, Ceribelli M, Pitarque-Marti M, et al. Selective effects of the anticancer drug Yondelis (ET-743) on cell-cycle promoters. Mol Pharmacol. 2005;68:1496-1503.

70. Forni C, Minuzzo M, Virdis E, et al. Trabectedin (ET-743) promotes differentiation in myxoid liposarcoma tumors. Mol Cancer Ther. 2009;8:449-457.

71. Herrero AB, Martin-Castellanos C, Marco E, Gago F, Moreno S. Cross-talk between nucleotide excision and homologous recombination DNA repair pathways in the mechanism of action of antitumor trabectedin. Cancer Res. 2006;66:8155-8162.
72. Schöffski P. DNA repair functionality modulates the clinical outcome of patients with advanced sarcoma treated with trabectedin (ET-743). Journal of Clinical Oncology, 2006 ASCO Annual Meeting Proceedings Part I Vol 24, No 18S (June 20 Supplement), 2006:9522.

73. Meco D, Colombo T, Ubezio P, et al. Effective combination of ET-743 and doxorubicin in sarcoma: preclinical studies. Cancer Chemother Pharmacol. 2003;52:131-138.

74. Riccardi A, Meco D, Ubezio P, et al. Combination of trabectedin and irinotecan is highly effective in a human rhabdomyosarcoma xenograft. Anticancer Drugs. 2005;16:811-815.

75. Takahashi N, Li WW, Banerjee D, Scotto KW, Bertino JR. Sequencedependent enhancement of cytotoxicity produced by ecteinascidin 743 (ET-743) with doxorubicin or paclitaxel in soft tissue sarcoma cells. Clin Cancer Res. 2001;7:3251-7.

76. Sessa C, Perotti A, Noberasco C, et al. Phase I clinical and pharmacokinetic study of trabectedin and doxorubicin in advanced soft tissue sarcoma and breast cancer. Eur J Cancer. 2008 Dec 27. [Epub ahead of print].

77. von Mehren M, Schilder RJ, Cheng JD, et al. A phase I study of the safety and pharmacokinetics of trabectedin in combination with pegylated liposomal doxorubicin in patients with advanced malignancies. Ann Oncol. 2008;19:1802-9.

78. Papadopoulos. Phase I and pharmacokinetics (PK) study of sequential paclitaxel and trabectedin every 2 weeks in patients with advanced solid tumors. J Clin Oncol. 2006; ASCO Annual Meeting Proceedings Part I, 2006;24:(June 20 Supplement)18S, 2029.

79. Gore L. Phase I combination study of trabectedin (T) and capecitabine (C) in patients with advanced malignancies. J Clin Oncol. 2006; ASCO Annual Meeting Proceedings Part I, 2006;24:(June 20 Supplement)18S, 2079.
OncoTargets and Therapy

\section{Publish your work in this journal}

OncoTargets and Therapy is an international, peer-reviewed, open access journal focusing on the pathological basis of all cancers, potential targets for therapy and treatment protocols employed to improve the management of cancer patients. The journal also focuses on the impact of management programs and new therapeutic agents and protocols on

\section{Dovepress}

patient perspectives such as quality of life, adherence and satisfaction. The manuscript management system is completely online and includes a very quick and fair peer-review system, which is all easy to use. Visit http://www.dovepress.com/testimonials.php to read real quotes from published authors. 